\title{
Megalencephaly and Epileptic Encephalopathy: Bad luck or a common pathway?
}

Ekeke $\mathrm{P}^{1}$, Naik $\mathrm{M}^{2,3}$, Vats $\mathrm{KR}^{4,5}$

${ }^{1}$ Division of Newborn Medicine, UPMC Children's Hospital of Pittsburgh

${ }^{2}$ Director, Neonatal Neurology Program, Children's Hospital of Pittsburgh of UPMC

${ }^{3}$ Assistant Professor, University of Pittsburgh School of Medicine

${ }^{4}$ Division of Newborn Medicine, UPMC Magee-Women's Hospital

${ }^{5}$ Assistant Professor, University of Pittsburgh School of Medicine

Corresponding Author: Paris Ekeke

Address: Department of Pediatrics, Division of Newborn Medicine, UPMC Children's Hospital of Pittsburgh, 4401 Penn Avenue, Pittsburgh, Pennsylvania 15224, Ph: 574-286-4104; E-mail: kingsberryps@upmc.edu

Received date: 29 September 2019; Accepted date: 18 November 2019; Published date: 24 November 2019

Citation: Ekeke P, Naik M, Vats KR. Megalencephaly and Epileptic Encephalopathy: Bad luck or a common pathway?. Asp Biomed Clin Case Rep. 2019 Nov 24;2(3):129-135.

Copyright (C) 2019 Ekeke P, Naik M, Vats KR. This is an open-access article distributed under the Creative Commons Attribution License, which permits unrestricted use, distribution, and reproduction in any medium provided the original work is properly cited.

\begin{abstract}
Megalencephaly is a neuronal migration disorder characterized by an abnormally large brain. Numerous associated syndromes and various molecular mutations have been identified as an etiology for megalencephaly, however, SCN2A mutations have not been previously described. This report highlights a case of a term male megalencephalic neonate who presents with intractable seizures, who was found to have SCN2A gene variant that has now been identified as pathogenic. This patient expands our knowledge of the phenotypic spectrum of SNC2A mutations by adding consideration for macroscopic brain findings. Currently, we have no direct link between SCN2A mutations and megalencephaly, but our patient highlights the potential overlap in disease processes. It is possible that the biochemical disturbance associated with abnormal neuronal migration also affects the neuronal circuitry, thus increasing the propensity for electrical dysfunction and manifesting as seizures.
\end{abstract}

\section{Keywords}

Megalencephaly; Epileptic encephalopathy; SCN2A mutations; Neuronal migration

\section{Abbreviations}

PI3K: Phosphatidylinositol 3-Kinase; MCAP: Megalencephaly-Capillary Malformation; MPPH: Megalencephaly Polydactyly Polymicrogyria Hydrocephalus

\section{Introduction}

Bilateral megalencephaly is a rare malformation of the central nervous system that affects 1 out of 50 children in the general. It is a disorder of abnormal brain proliferation and neuronal cell migration, defined as brain weight more than 2 standard deviations above the age-related mean [1]. The PI3KAKT pathway mutation is known to cause two clinically distinct syndromes: megalencephalycapillary malformation (MCAP) and megalencephalypolydactyly- polymicrogyria- hydrocephalus (MPPH). MCAP is characterized by cutaneous vascular 
Citation: Ekeke P, Naik M, Vats KR. Megalencephaly and Epileptic Encephalopathy: Bad luck or a common pathway?. Asp Biomed Clin Case Rep. 2019 Nov 24;2(3):129-135.

\section{Case Report}

malformations, connective tissue dysplasia, and somatic overgrowth which distinguish it from MPPH. Seizure is not a classic presentation of either syndrome [2]. We report a novel SCN2A gene variant association in a neonate with megalencephaly and intractable seizures.

\section{Case Presentation}

A term, small for gestational age, non-dysmorphic male infant was born to non-consanguineous parents at 37 weeks gestation via Cesarean section for breech presentation. His birth weight was $2422 \mathrm{~g}$, length $45.8 \mathrm{~cm}$ head circumference $33 \mathrm{~cm}$ and Apgar scores were 5 at 1 minute, 9 at 5 minutes. Physical examination was normal. He received routine delivery room care and was admitted to the new-born nursery. Around 24 hours of age, the infant was admitted to the Neonatal Intensive Care Unit (NICU) for the management of hypoglycemia. While in the NICU, he developed multiple bradycardic episodes which progressively increased in frequency, prompting further evaluation.

Blood work was significant for hyponatremia with sodium of 122 with normal renal function, calcium, phosphorus, magnesium, CBC, differential and platelet counts. EKG showed normal sinus rhythm. Head ultrasound was normal. Electroencephalography (Fig-

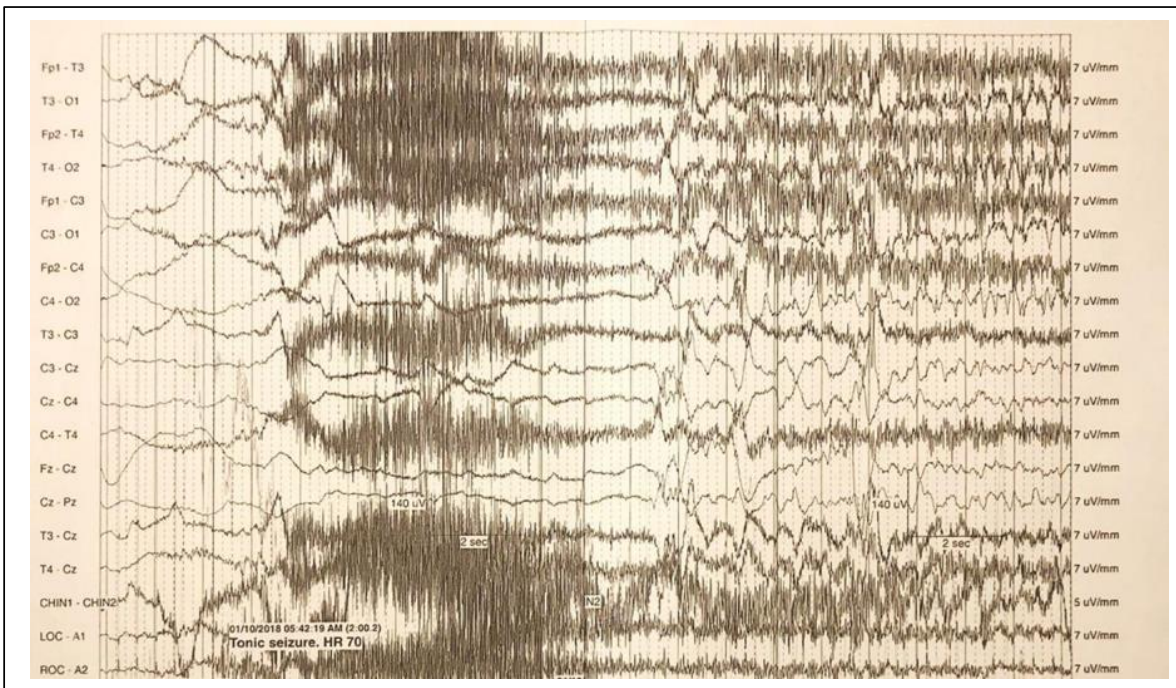

Fig-1: Electroencephalography (EEG) demonstrating migrating partial seizures.

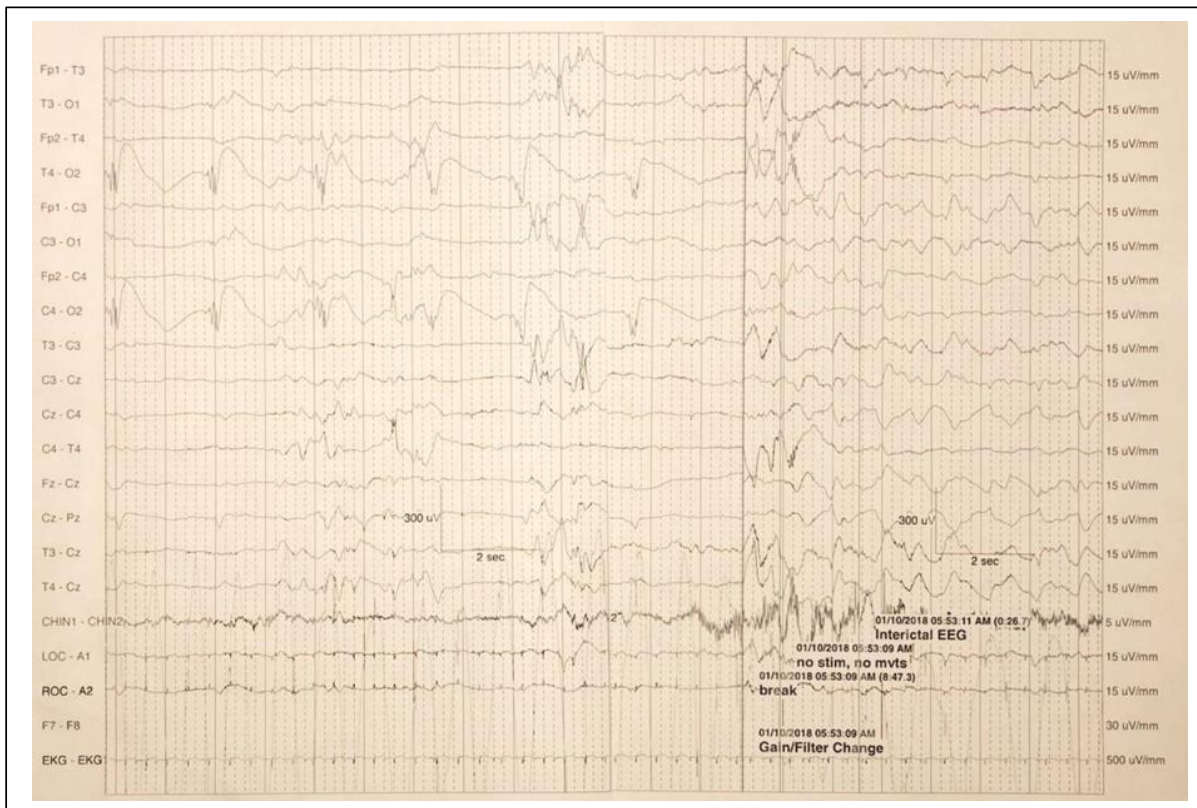

Fig-2: Electroencephalography (EEG) demonstrating abnormal interictal period. 
Citation: Ekeke P, Naik M, Vats KR. Megalencephaly and Epileptic Encephalopathy: Bad luck or a common pathway?. Asp Biomed Clin Case Rep. 2019 Nov 24;2(3):129-135.

1,2) confirmed malignant migrating partial seizures correlating with clinical bradycardic events that were refractory to multiple anti-epileptic medications including: two Phenobarbital loading doses at $20 \mathrm{mg} / \mathrm{kg} /$ dose with maintenance dosing at $4 \mathrm{mg} / \mathrm{kg} /$ day twice daily , Keppra $6 \mathrm{omg} / \mathrm{kg} /$ day divided twice daily, Leucovorin $5 \mathrm{mg}$ twice daily, Topamax 10mg/kg, Pyridoxal-5-phosphate 2omg every 6 hours, Bumetanide infusion at
$0.1 \mathrm{mg} / \mathrm{kg} /$ hour, and continuous versed infusion running at $1.5 \mathrm{mg} / \mathrm{kg} /$ hour. He was also given fosphenytoin a single loading dose of $20 \mathrm{mg} / \mathrm{kg} / \mathrm{dose}$ and subsequent load of $10 \mathrm{mg} / \mathrm{kg} /$ dose when seizures persisted. Ultimately, further fosphenytoin doses were held due to supratherapeutic levels.

He required intubation and ventilatory support for respiratory depression in the setting of multiple
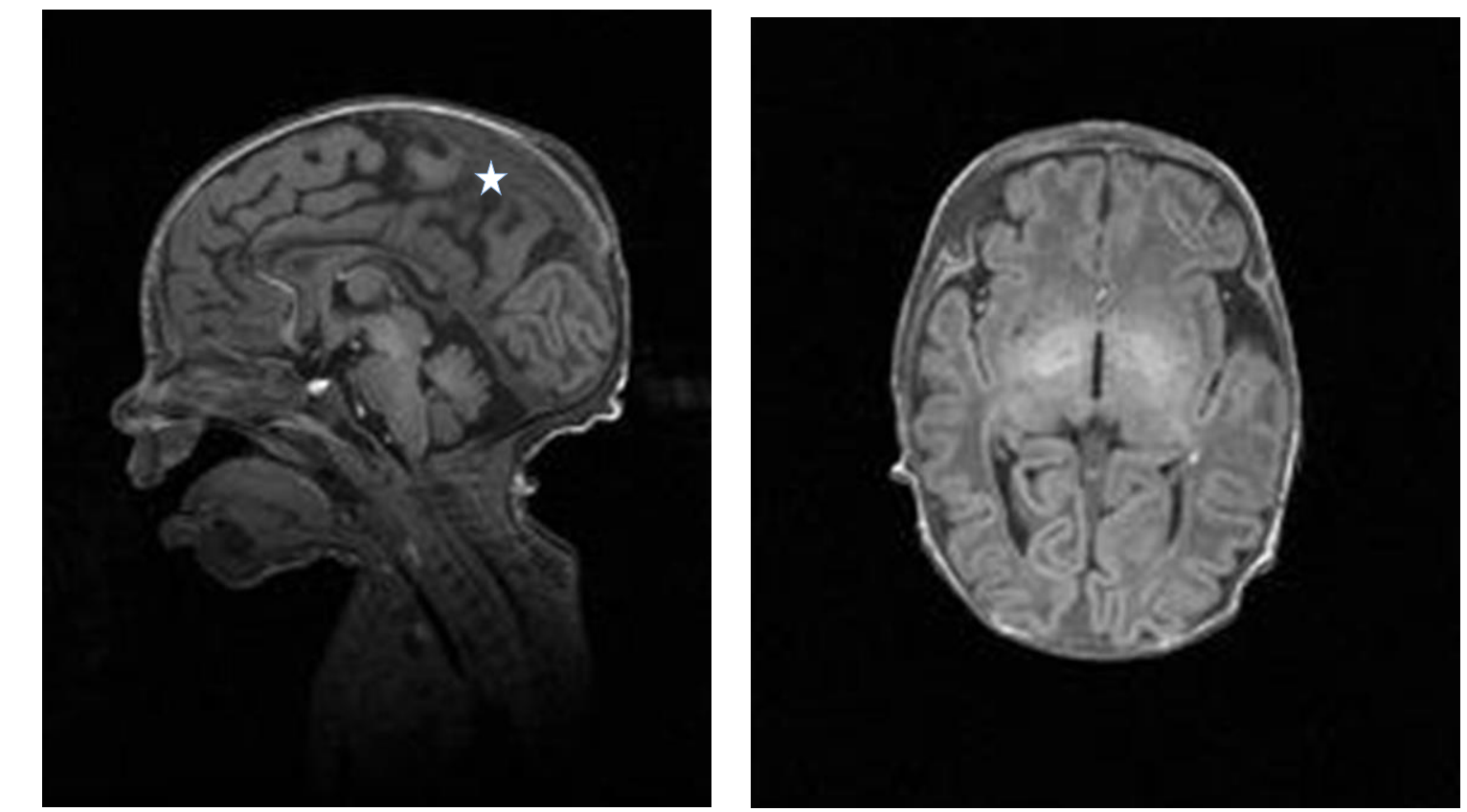

Fig-3:

T1 sagittal and axial MRI images demonstrating multiple punctate areas of increased T1 signal consistent with white matter injury.

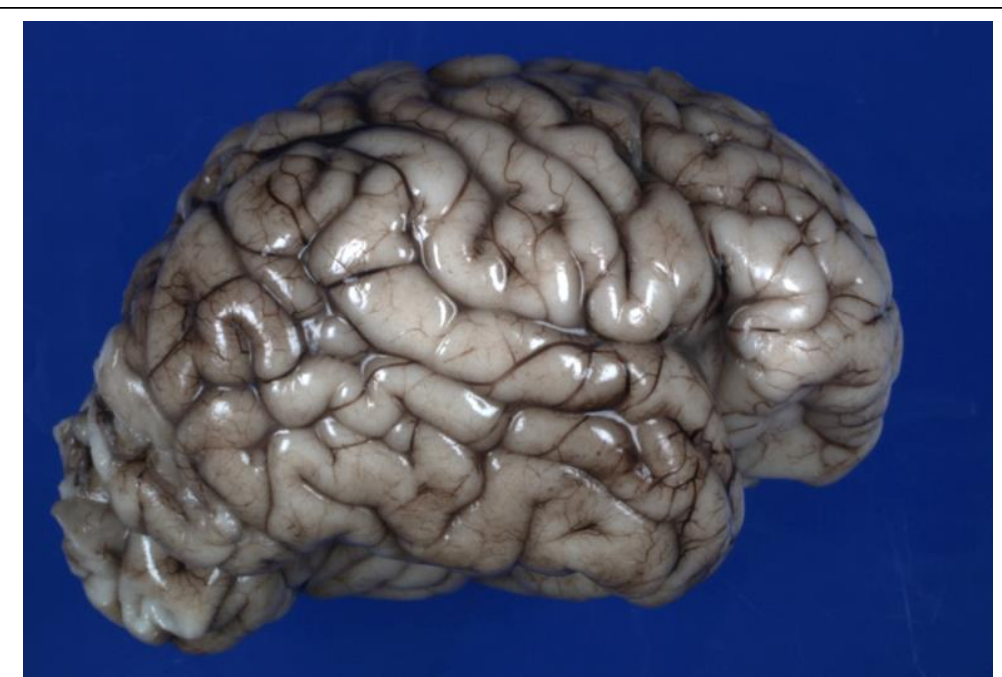

Fig-4: Gross anatomy of Brain:

The 50o-gram formalin fixed neonatal brain is depicted below. The leptomeninges are thin and transparent. There is no appreciable vascular congestion. No evidence of brain edema or herniation is found. Some of the gyri appear thick, but not pachygyric. There is no abnormality patterning. The vessels distribute normally at the base of the brain. 
Citation: Ekeke P, Naik M, Vats KR. Megalencephaly and Epileptic Encephalopathy: Bad luck or a common pathway?. Asp Biomed Clin Case Rep. 2019 Nov 24;2(3):129-135.

\section{Case Report}

medications required for treatment of his intractable seizures. MRI demonstrated no structural abnormalities but multiple areas of bilateral punctate white matter injury with increased T1 signal, some with restricted diffusion (Fig-3,4). CSF studies were unremarkable. Due to the presence of persistent seizures, refractory to escalating doses of antiepileptic medications, the possibility of a genetic epilepsy syndrome was considered. Despite maximum medical intervention the infant's status deteriorated. After discussion with family about the guarded longterm outcome, the infant's care was redirected to comfort measures only. Infant was terminally extubated and died on day of life 10.

Autopsy reported megalencephaly with neonatal
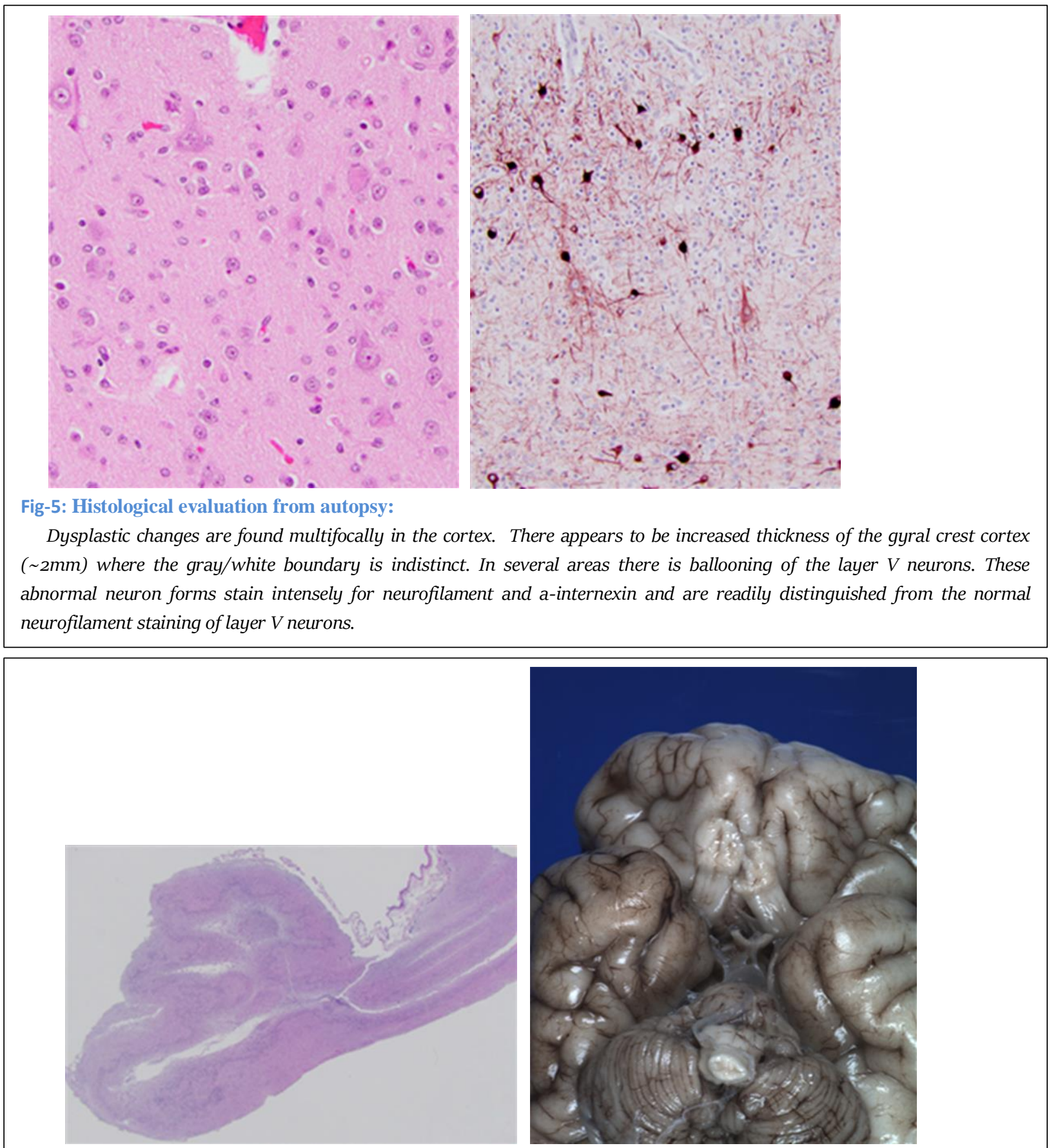

Fig-6:

The markedly enlarged olfactory bulb showed extensive dysplastic features histologically. These appear to be peripheral displacement of mitral neurons without glomerular development and reduplication of the granular cell layers. There was an abundance of migrating precursors in the nerve. 
brain weight of 500 grams, olfactory bulb hypertrophy and dysplasia, multifocal dysplastic areas of cortex and widespread subacute destructive processes in the hippocampal complex, dorsal thalamus, optic nerve, cerebellar purkinje layer with evidence of focal white matter infarcts (Fig-5,6). Serum epilepsy panel revealed SCN2A mutation. Whole exome sequencing performed on brain tissue reported infant was heterozygous for a de novo L210R pathogenic variant in the SCN2A gene.

\section{Discussion}

When considering megalencephaly, discovering the underlying etiology can often be challenging. Although previous reports have implicated mutations in the PI3K-AKT pathway, we now know there is significant heterogeneity in etiology and presentation. Over the past century, numerous associated syndromes and many molecular mutations have been identified as causes for megalencephaly but SCN2A mutations have not been previously reported [1-3].

The SCN2A gene encodes the alpha subunit of the voltage gated sodium channel which is involved with neuronal firing [4]. SCN2A variants are inherited in an autosomal dominant manner. Pathogenic variants causing encephalopathy are typically de novo, while inherited variants often result in milder phenotypes and may exhibit incomplete penetrance [5]. To our knowledge, the L210R variant in the SCN2A gene has not been classified as a pathogenic variant prior to this patient. On review of large scale human genomic datasets, we know that the L210R variant is not observed in large population cohorts [6]. The L210R variant is a non-conservative amino acid substitution, which is likely to impact secondary protein structure as these residues differ in polarity, charge, size and/or other properties. This substitution in $\mathrm{p}$. Leu210Arg (L210R) (CTG>CGG): c.629 T>G in exon 6 of the $\mathrm{SCN} 2 \mathrm{~A}$ gene is predicted to be within the extracellular loop between the $\mathrm{S}_{3}$ and $\mathrm{S}_{4}$ transmembrane segments of the first homologous domain. Additionally, missense variants in nearby residues that have a gain-of-function effect lead to a spectrum of SCN2A-related disorders, ranging from benign familial neonatal-infantile seizures (BFNIS) to epileptic encephalopathies, including Ohtahara syndrome and epilepsy of infancy with migrating focal seizures (EIMFS) [4,6,7]. Therefore, in consideration of the available literature in combination with the clinical context, we conclude L210R as a pathogenic variant and the likely cause of refractory seizures in our patient. In our case, there was a lack of phenotypic diagnostic clues given the infant's normal prenatal anatomy scan, normal physical exam and non-specific brain imaging. Therefore, if the clinical suspicion is high, genetic testing via the comprehensive epilepsy panel should be considered for a definitive diagnosis.

To date, there is sparse data on an association between SCN2A-related disorders and megalencephaly. There is no comprehensive overview of possible SCN2A phenotypes and the genotypephenotype correlation remains poorly understood. In general, there are 4 recognized phenotype groups: 1) benign neonatal or infantile epilepsies, 2) neurodevelopmental /neuropsychiatric disorders, including schizophrenia, autism and intellectual disability, 3) Infantile Spasms, and 4) early onset epileptic encephalopathies. Severe neonatal epileptic encephalopathies can also be associated with cortical abnormalities including cortical dysplasia but megalencephaly has not been described [8]. Similarly, there have been case reports with severe non-SCN2A related epilepsy as a consequence of hemimegalencephaly but only one case report to date documented neonatal epileptogenic disorder concurrent with bilateral megalencephaly [9]. Sawaishi et.al described a neonate with megalencephaly, persistent hyponatremia, and severe epilepsy responsive only to lidocaine, suggesting a sodium channelopathy as the etiology [10]. Although formal testing for channelopathies was not discussed, a SCN mutation is a plausible explanation.

Currently we have no direct link between SCN2A mutations and megalencephaly, but our patient highlights the potential overlap in disease processes. Many of the genes implicated in neuronal migration disorders such as megalencephaly have a strong genetic and biochemical component that directly affects the cytoskeleton of the brain. It is possible that the biochemical disturbance associated with abnormal neuronal migration also affects the neuronal circuitry, 
Citation: Ekeke P, Naik M, Vats KR. Megalencephaly and Epileptic Encephalopathy: Bad luck or a common pathway?. Asp Biomed Clin Case Rep. 2019 Nov 24;2(3):129-135.

Case Report

thus increasing the propensity for electrical dysfunction and manifesting as seizures. In regards, to intractable neonatal seizures and megalencephaly, it is prudent to consider if there is a common pathway that could explain our patient's clinical presentation. Our findings support a previous case described by Bernado et al. of a neonate with SCN2A epileptic encephalopathy with severe cortical dysplasia [8]. The diagnosis was heralded by a prenatal MRI at 32 weeks which demonstrated dysplasia, corpus callosum dysgenesis, and pachygyria. Our case highlights a severe presentation in the absence of abnormal prenatal and postnatal MRI findings. The identified variant thus further adds to our knowledge of the vast spectrum of SCN2Arelated disorders and highlights the need for continued investigation and discovery.

\section{References}

[1] Pavone P, Praticò AD, Rizzo R, Corsello G, Ruggieri M, Parano E, Falsaperla R. A clinical review on megalencephaly: A large brain as a possible sign of cerebral impairment. Medicine (Baltimore). 2017 Jun;96(26):e6814. [PMID: 28658095]

[2] Mirzaa GM, Rivière JB, Dobyns WB. Megalencephaly syndromes and activating mutations in the PI3K-AKT pathway: MPPH and MCAP. Am J Med Genet C Semin Med Genet. 2013 May;163C(2):122-30. [PMID: 23592320]

[3] Matalon D, Goldberg E, Medne L, Marsh ED. Confirming an expanded spectrum of SCN2A mutations: a case series. Epileptic Disord. 2014 Mar;16(1):13-18. [PMID: 24659627]

[4] Wolff M, Johannesen KM, Hedrich UBS, Masnada S, Rubboli G, Gardella E, Lesca G, Ville D, Milh M, Villard L, Afenjar A, Chantot-Bastaraud S, Mignot C, Lardennois C, Nava C, Schwarz N, Gérard M, Perrin L, Doummar D, Auvin S, Miranda MJ, Hempel M, Brilstra E, Knoers N, Verbeek N, van Kempen M, Braun KP, Mancini G, Biskup S, Hörtnagel K, Döcker M, Bast T, Loddenkemper T, Wong-Kisiel L, Baumeister FM, Fazeli W, Striano P, Dilena R, Fontana E, Zara F, Kurlemann G, Klepper J, Thoene JG, Arndt DH, Deconinck N, Schmitt-Mechelke T, Maier O, Muhle H, Wical B, Finetti C, Brückner R, Pietz J, Golla G, Jillella D, Linnet KM, Charles P, Moog U, Õiglane-Shlik E, Mantovani JF, Park K, Deprez M,
Lederer D, Mary S, Scalais E, Selim L, Van Coster R, Lagae L, Nikanorova M, Hjalgrim H, Korenke GC, Trivisano M, Specchio N, Ceulemans B, Dorn T, Helbig $\mathrm{KL}$, Hardies $\mathrm{K}$, Stamberger $\mathrm{H}$, de Jonghe $\mathrm{P}$, Weckhuysen S, Lemke JR, Krägeloh-Mann I, Helbig I, Kluger G, Lerche H, Møller RS. Genetic and phenotypic heterogeneity suggest therapeutic implications in SCN2A-related disorders. Brain. 2017 May 1;140(5):1316-36. [PMID: 28379373]

[5] Lek M, Karczewski KJ, Minikel EV, Samocha KE, Banks E, Fennell T, O'Donnell-Luria AH, Ware JS, Hill AJ, Cummings BB, Tukiainen T, Birnbaum DP, Kosmicki JA, Duncan LE, Estrada K, Zhao F, Zou J, Pierce-Hoffman E, Berghout J, Cooper DN, Deflaux N, DePristo M, Do R, Flannick J, Fromer M, Gauthier L, Goldstein J, Gupta N, Howrigan D, Kiezun A, Kurki MI, Moonshine AL, Natarajan P, Orozco L, Peloso GM, Poplin R, Rivas MA, Ruano-Rubio V, Rose SA, Ruderfer DM, Shakir K, Stenson PD, Stevens C, Thomas BP, Tiao G, Tusie-Luna MT, Weisburd B, Won HH, Yu D, Altshuler DM, Ardissino D, Boehnke M, Danesh J, Donnelly S, Elosua R, Florez JC, Gabriel SB, Getz G, Glatt SJ, Hultman CM, Kathiresan S, Laakso M, McCarroll S, McCarthy MI, McGovern D, McPherson R, Neale BM, Palotie A, Purcell SM, Saleheen D, Scharf JM, Sklar P, Sullivan PF, Tuomilehto J, Tsuang MT, Watkins HC, Wilson JG, Daly MJ, MacArthur DG; Exome Aggregation Consortium. Analysis of proteincoding genetic variation in 60,706 humans. Nature. 2016 Aug 18;536(7616):285-91. [PMID: 27535533]

[6] Shi X, Yasumoto S, Kurahashi H, Nakagawa E, Fukasawa T, Uchiya S, Hirose S. Clinical spectrum of SCN2A mutations. Brain Dev. 2012 Aug;34(7):541-45. [PMID: 22029951]

[7] Stenson PD, Mort M, Ball EV, Evans K, Hayden M, Heywood S, Hussain M, Phillips AD, Cooper DN. The Human Gene Mutation Database: towards a comprehensive repository ] of inherited mutation data for medical research, genetic diagnosis and nextgeneration sequencing studies. Hum Genet. 2017 Jun;136(6):665-77. [PMID: 28349240]

[8] Bernardo S, Marchionni E, Prudente S, De Liso P, Spalice A, Giancotti A, Manganaro L, Pizzuti A. Unusual association of $\mathrm{SCN} 2 \mathrm{~A}$ epileptic encephalopathy with severe cortical dysplasia detected by prenatal MRI. Eur J Paediatr Neurol. 2017 May;21(3):587-9o. [PMID: 28254201] 
Citation: Ekeke P, Naik M, Vats KR. Megalencephaly and Epileptic Encephalopathy: Bad luck or a common pathway?. Asp Biomed Clin Case Rep. 2019 Nov 24;2(3):129-135.

[9] Di Rocco C, Battaglia D, Pietrini D, Piastra M, Massimi L. Hemimegalencephaly: clinical implications and surgical treatment. Childs Nerv Syst. 2006 Aug;22(8):852-66. [PMID: 16821075]

[10] Sawaishi Y, Yano T, Enoki M, Takada G. Lidocaine-dependent early infantile status epilepticus with highly suppressed EEG. Epilepsia. 2002 Feb;43(2):201-04. [PMID: 11903470] 